Int. J. Morphol.,

35(3):812-819, 2017.

\title{
The Tibial Nerve and Its Vasculature: An Anatomical Evaluation
}

\author{
El Nervio Tibial y su Vasculatura: Una Evaluación Anatómica
}

\author{
Wagih G. Elbarrany \& Faris M. Altaf
}

ELBARRANY, W. G. \& ALTAF, F. M. The tibial nerve and its vasculature: An anatomical evaluation. Int. J. Morphol., 35(3):812-819, 2017.

SUMMARY: The study has contributed to evaluate the tibial nerve and its vasculature anatomically. Ten preserved cadavers $(5$ male, 5 female) have been used for this study. Each cadaver was injected with red latex and through incisions the tibial nerve was exposed at the level of bifurcation of sciatic nerve. The tibial nerve in $85 \%$ cadavers was located between middle and lower thirds at upper angle of popliteal fossa; whereas, in $15 \%$ cadavers it was present below the piriformis muscle in gluteal region. The total length of the tibial nerve was at a mean of $65.26 \pm 14.42 \mathrm{~cm}$ in males and $64.79 \pm 67.61 \mathrm{~cm}$ in females, without significantly different. Its total diameter was at a mean of $5.51 \pm 1.55 \mathrm{~mm}$, with a mean of $4.11 \pm 0.88 \mathrm{~mm}$ at the popliteal fossa and a mean of $3.24 \pm 0.81 \mathrm{~mm}$ at its termination deep to the flexor retinaculum in male cadavers. In female; the means were $5.11 \pm 0.21 \mathrm{~mm}, 3.97 \pm 1.78 \mathrm{~mm}$ and $3.14 \pm 0.03$ $\mathrm{mm}$ respectively without significance difference. It was concluded that tibial nerve has sufficient and good blood supply. Moreover, it can be utilized as allogeneic vascularized nerve graft to repair sizable nerves after limb salvage.

KEY WORDS: Tibia; Fibular artery; Posterior tibial artery; Vascularized nerve grafts.

\section{INTRODUCTION}

Morphology is a diversified sub-classification of science, which includes the structural study of different organisms and their specific features. Moreover, morphology also deals with the relationship between the features that are associated with each other for developing of systematic structures. The main contribution of this study is in the domain of anatomical evaluation. The study has mainly focused on the anatomic evaluation of tibial nerve, which would be helpful for the professionals to develop differential techniques for grafting. Thus, the study has aimed to evaluate tibial nerve and its vasculature anatomically.

The tibial nerve is considered as the largest sciatic nerves' terminal branch, which is derived from the ventral branches of the $4^{\text {th }}$ and $5^{\text {th }}$ lumbar region, and $1^{\text {st }}$ to $3^{\text {rd }}$ sacral ventral rami. It descends along the back of the thigh and the popliteal fossa to the distal border of the popliteus muscle (Ndiaye et al., 2003; Standring, 2005). It further passes deep to gastrocnemius and soleus muscles, and then anterior to the arch of soleus muscle with the popliteal artery. Furthermore, it also runs into the leg where it descends with the posterior tibial vessels to end deep to the flexor retinaculum, by dividing into medial and lateral plantar nerves. Sometimes, the tibial nerve is given the name of the posterior tibial nerve at the lower border of popliteus muscle (Standring). In $90 \%$ of cases, its bifurcation was recorded deep to the flexor retinaculum $1 \mathrm{~cm}$ from the line, between the medial malleolus and the medial calcaneal tubercle (Ndiaye et al.). The tibial nerve becomes superficial in the distal part of the leg; covered only by skin and fascia supplying the muscles of the flexor compartment of the leg (Apaydin et al., 2008).

The tibial nerve can be subjected to stretch during the lower limb movements or different limb positions; specially, ankle joint dorsiflexion and inversion of the foot. Consequently, the nerve has to adapt itself to such changes through its mechanical properties. It can adapt repeated forces and also can slide in relation to the surrounding tissues (Shacklock, 2005; Apaydin et al.). Forces and stretch can jeopardize the blood supply to the nerve, leading to ischemia that can affect the nerve function. The tibial nerve has its clinical importance. Its branches to both heads of the gastrocnemius and the posterior soleus muscle were suggested to be used as donors, to restore the function of the deep fibular nerve in cases of high sciatic nerve injury (Flores, 2009). 
The anatomy of the tibial nerve is important for successful clinical management. It was reported that, percutaneous tibial nerve stimulation can improve the sexual function of females with the overactive urinary bladder. Transcutaneous stimulation of the posterior tibial nerve (tibial nerve name distal to the lower border of popliteus muscle) was also reported to improve the conditions of overactive bladder in children (Patidar et al. 2015), including the refractory cases (Boudaoud et al., 2015). The endoneurial microenvironment and the internal milieu include the endoneurial blood flow that represents a cornerstone of nerve function and the regenerative power after injury (Yasuda \& Dyck, 1987). The peripheral nerves receive blood supply from regional arteries. Thus, affection of the feeding blood vessels is of great importance in different kinds of neuropathies (Bradley et al., 2000; Kogawa et al., 2000). It was also reported that vascularized nerve grafts have better regenerative power and shorter time for recovery (Schupeck et al., 1989). The size, length, and the group of muscles supplied by the peripheral nerve together with its vascularity can affect choosing the suitable nerve for vascularized nerve grafts. Therefore, the aim of the study was to examine some morphometric measures of the tibial nerve together with its detailed arterial supply; thus, helping its clinical applications and its possible use as a vascularized nerve graft.

\section{MATERIAL AND METHOD}

Twenty lower limbs from 10 preserved plastinated cadavers ( 5 males and 5 females) have been used for this study. The research has followed the regulations of the ethical committee of the Faculty of Medicine, Umm Al-Qura University that is following the international ethical rules of the researches on the human cadavers.

The external iliac artery of each cadaver was injected with red latex to visualize the arterial tree of the lower limbs. A longitudinal incision has been done on the posterior surface of each limb to dissect the tibial nerve from its origin till its termination. The back of the thigh, the popliteal fossa, and the back of lower leg has been dissected. The skin and subcutaneous tissue were removed. The tibial nerve was exposed at the level of bifurcation of the sciatic nerve and at its terminal division deep to the flexor retinaculum, between the medial malleolus and medial process of calcaneal tuberosity.

Quantitative and qualitative measurements. The following measurements have been done in each dissected nerve (the male and female cadavers): a) The distance from tibial nerve origin (at the end of the sciatic nerve) to its terminal division deep to the flexor retinaculum. The length of tibial nerve was measured by a standard metric tape.

b) The diameter and thicknesses of tibial nerve in a site of the bifurcation, at popliteal fossa, and at the site of terminal division has been determined. The diameter and thicknesses of tibial nerve in the three positions were measured by Vernier Swiss digital caliper with (0.05) accuracy.

c) The number of the vascular pedicles to the tibial nerve and the source of each were also identified.

Statistical analysis. The mean and standard deviations of all the measurements have been performed. Finding of measurements have been statistically calculated using the ttest with the significant value of $p \leq 0.05$ and the results, tables, and histograms have been developed.

\section{RESULTS}

The morphometric measurements. The tibial nerve in 17 dissected cadavers $(85 \%)$ originated in the thigh between the middle and lower thirds at the upper angle of the popliteal fossa (Fig. 1A). It emerged below the piriformis muscle in the gluteal region in three dissected cadavers (15\%) (Fig. 1C).

The total length of the tibial nerve its origin (bifurcation of the sciatic nerve) (Fig. 1) till the its termination deep to the flexor retinaculum (Fig. 2) was at a mean of $65.26 \pm 14.42 \mathrm{~cm}$ (ranged from 55.1 to $72.01 \mathrm{~cm}$ ) in males and $64.79 \pm 67.61 \mathrm{~cm}$ (ranged from 55.7 to $70.04 \mathrm{~cm}$ ) in females, the two are not significantly different $(\mathrm{p}<0.9822)$. The total diameter of the tibial nerve in male cadavers was at a mean of $5.51 \pm 1.55 \mathrm{~mm}$ (ranged from 5.40 to 5.55) at its origin, at a mean of 4.11 $\pm 0.88 \mathrm{~mm}$ (ranged from 4.01 to $4.2 \mathrm{~mm}$ ) at the popliteal fossa and at a mean of $3.24 \pm 0.81 \mathrm{~mm}$ (ranged from $3.1-3.34 \mathrm{~mm}$ ) at its termination deep to the flexor retinaculum. The total diameter of the tibial nerve in female cadavers was at a mean of $5.11 \pm 0.21 \mathrm{~mm}$ (ranged from 4.90 to 5.23) at its origin, at a mean of $3.97 \pm 1.78 \mathrm{~mm}$ (ranged from 3.43 to $4.10 \mathrm{~mm}$ ) at the popliteal fossa and at a mean of $3.14 \pm 0.03 \mathrm{~mm}$ (ranged from $2.98-2.32 \mathrm{~mm}$ ) at its termination deep to the flexor retinaculum. There were no significant differences between measurements in the males and females $(\mathrm{p}<0.4388, \mathrm{p}<0.827$ and $p<0.336$ respectively), as shown in Table II.

There was no significant difference between the total diameter in the right and the left sides both in males and females ( $p<0.9648$ and $p<0.3232$ respectively). Also there 

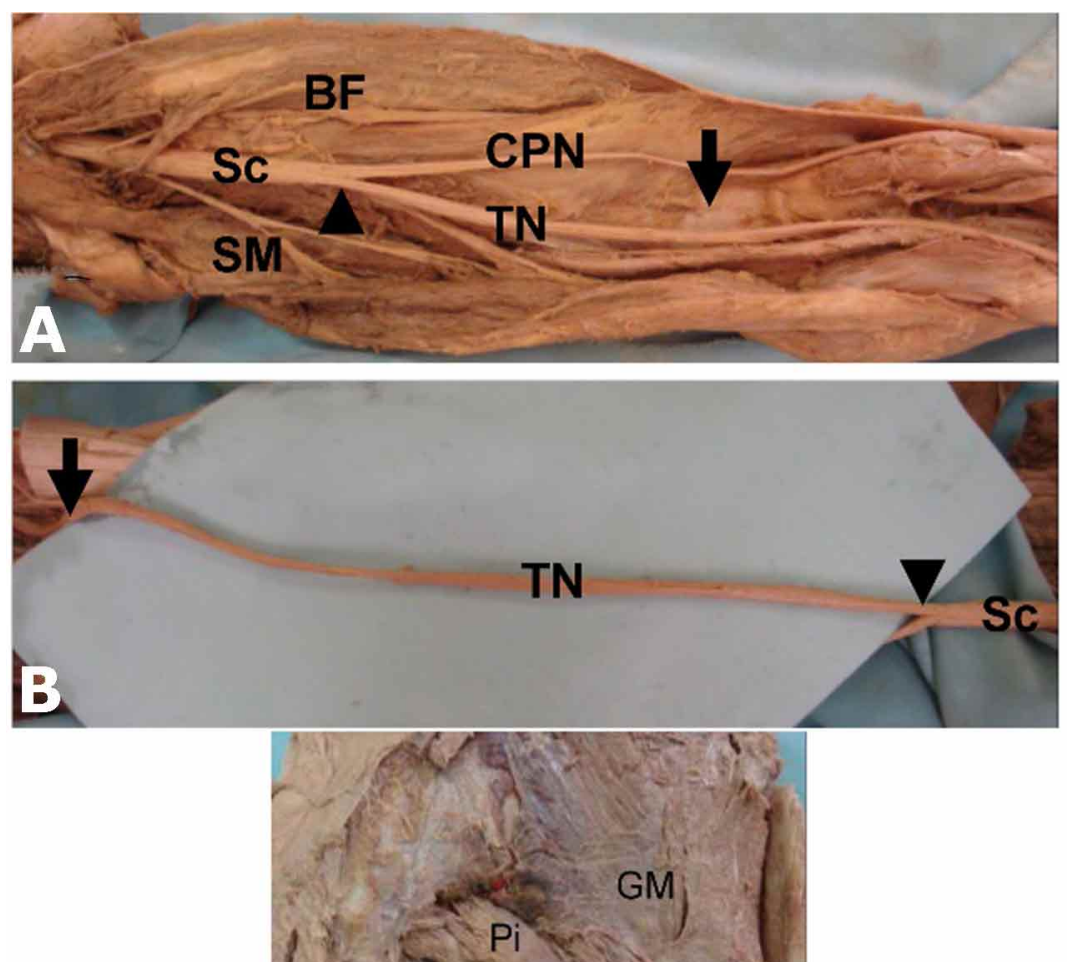

Fig. 1. Sciatic nerve and tibial never A: It shows the bifurcation (arrow head) of the sciatic nerve $(\mathrm{Sc})$ at the middle of the thigh into common fibular nerve (CFN) and the tibial nerve (TN). B shows the tibial nerve from its origin (arrow head) to the popliteal region (arrow). C shows high bifurcation of the sciatic nerve.

Table I. Diameter of the tibial nerve at different sites in mm (mean and standard deviation) in the male and female cadavers.

\begin{tabular}{lcccc}
\hline The site & Males & Females & P value & significance \\
\hline 1. Origin & $5.51 \pm 1.55$ & $5.11 \pm 0.21$ & $\mathrm{p}<0.4388$ & not \\
2. Popliteal fossa & $4.11 \pm 0.88$ & $3.97 \pm 1.78$ & $\mathrm{p}<0.827$ & not \\
3. Termination & $3.24 \pm 0.81$ & $3.14 \pm 0.03$ & $\mathrm{p}<0.336$ & not \\
\hline
\end{tabular}

Table II. Diameter of the tibial nerve at different sites in mm between the right and left tibial nerves (mean and standard deviation).

\begin{tabular}{lcccc}
\hline The site & \multicolumn{2}{c}{ Males } & \multicolumn{2}{c}{ Female s } \\
& Right limb & Left limb & Right limb & Left limb \\
\hline 1. Origin & $5.77 \pm 1.23$ & $5.34 \pm 1.78$ & $5.33 \pm 0.43$ & $5.23 \pm 0.11$ \\
2. Popliteal fossa & $4.56 \pm 0.64$ & $4.88 \pm 0.46$ & $3.86 \pm 1.89$ & $4.01 \pm 1.11$ \\
3. Termination & $3.84 \pm 0.32$ & $3.24 \pm 0.11$ & $3.22 \pm 0.09$ & $3.56 \pm 0.11$ \\
\hline
\end{tabular}

$\mathrm{P}<0.9999$ insignificant changes 


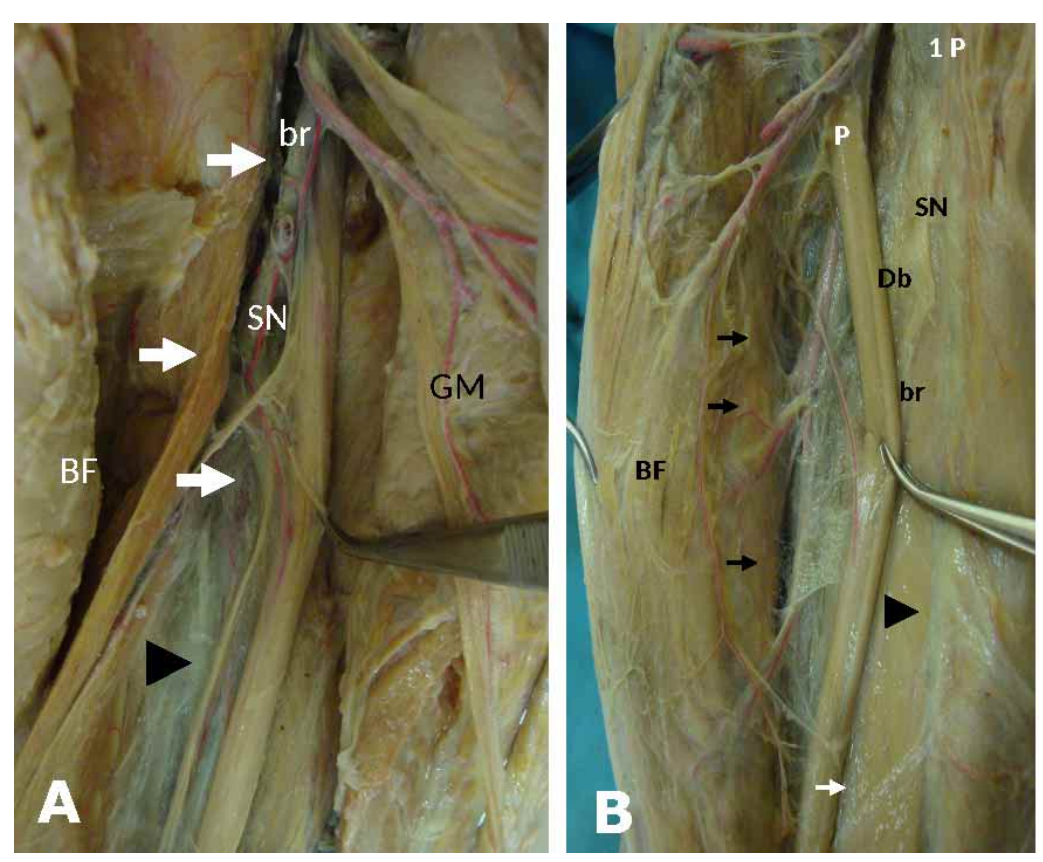

Fig. 2. Vascular Pedicle and Branches of Anastomotic Branch A shows a vascular pedicle (arrows) from a branch (br) from the inferior gluteal artery descends to supply the sciatic nerve (SN) (arrow head) of BF; biceps femoris, GM; gluteus maximus muscle. B. shows branch (br) from the descending anastomotic branch ( $\mathrm{Db}$ ) of the first perforator (1P) and an anastomotic branch (arrows) to the sciatic nerve (SN).

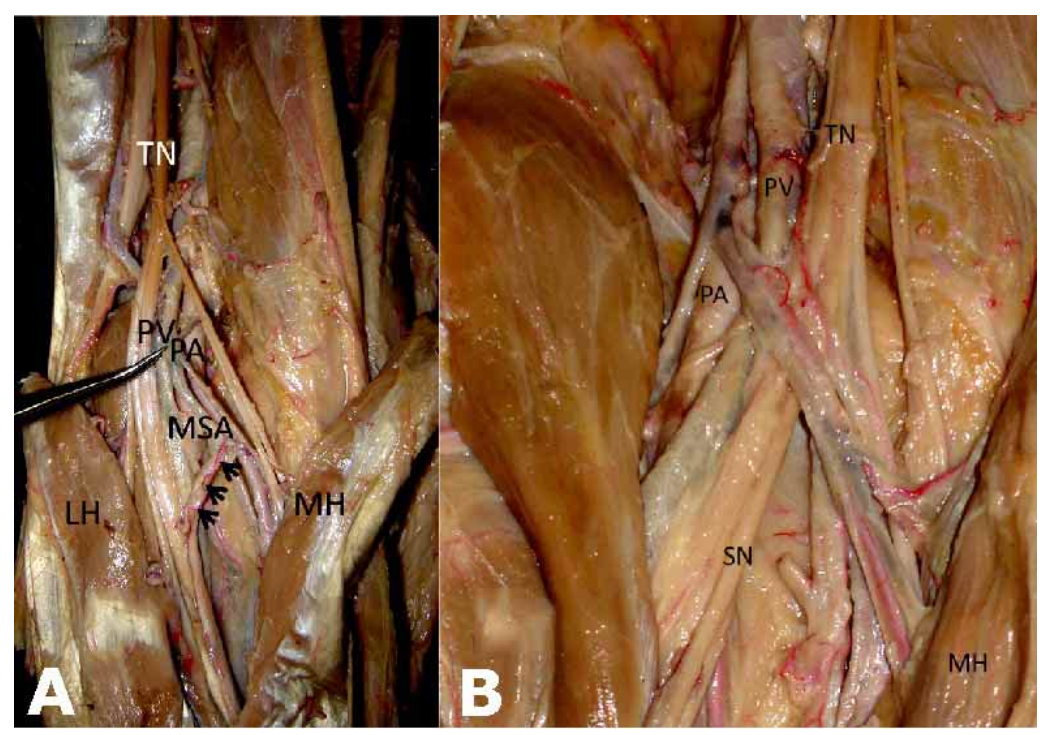

Fig. 3. Tibial Nerve and Arterial Pedicle A. It shows arterial pedicle (arrows) to the tibial nerve $(\mathrm{TN})$ from the medial sural artery (MSA), a branch from the popliteal artery (POA).B. shows arterial pedicle (arrow head) from branches of the popliteal artery. $\mathrm{MH}, \mathrm{LH}$; medial and lateral heads of gastronomies; PV; popliteal vein

was no significant difference between the right and left sides in either of the males and females ( $\mathrm{p}<0.5429$ and $\mathrm{p}<0.6714$ respectively) (Table II).
The blood supply of the posterior tibial nerve

The inferior gluteal and first perforator arteries: The tibial portion of the sciatic nerve got arterial supply from the inferior gluteal artery through its branch, that accompanied the posterior cutaneous nerve of the thigh (Fig. 2A) and from the descending branch of the first perforator branch of the deep artery of thigh (Arteria produnda femoris) (Fig. 2B).

The popliteal artery: At the popliteal fossa, the popliteal artery gave the medial sural artery that sent an arterial pedicle to the tibial nerve. It was accompanied by two venae comitantes that drained into the vena comitantes accompanying the medial sural artery (Fig.3A). The popliteal artery also gave a branch that ramified on the tibial nerve (Fig. 3B).

The fibular artery: It had a mean diameter of $3.38 \pm 0.1 \mathrm{~mm}$ (ranging from 2.5 to $4.5 \mathrm{~mm}$ ) at its beginning from the posterior tibial artery. It gave arterial pedicles to the tibial nerve at a mean of $4 \pm 0.1$ (ranged from 3 to 6 ). The mean diameter of these pedicles was $0.6 \mathrm{~mm}$ (ranging from 0.5 to 0.7 ). Some of these pedicles reached the nerve via mesentery in the outer sheath of the tibial nerve. They divided into an ascending and descending branches that shared with other pedicles in the formation of a central longitudinal artery (Figs 4, 5B). Fascicular branches from the central artery passed to supply the different nerve fascicles inside the tibial nerve. Other branches passed directly into the nerve to join the central tortuous artery (Fig. 5C).

The posterior tibial artery: It had a mean diameter of $4.24 \pm 0.2 \mathrm{~mm}$ (ranging from 3.5 to $5 \mathrm{~mm}$ ) at its beginning from the popliteal artery. It gave arterial pedicles to the tibial nerve at a mean of 3 (ranged from 2 to 5 pedicles) with a mean diameter of $0.7 \mathrm{~mm}$ (ranging from 0.5 to $0.8)$. These pedicles entered the nerve and joined the central longitudinal tortuous artery (Fig. 5A, 5C).

The venous drainage of the tibial nerve. The feeding arterial pedicles to the nerve were accompanied by two vena comitantes that drained into the regional veins (Figs. 4, 5 and 6). 

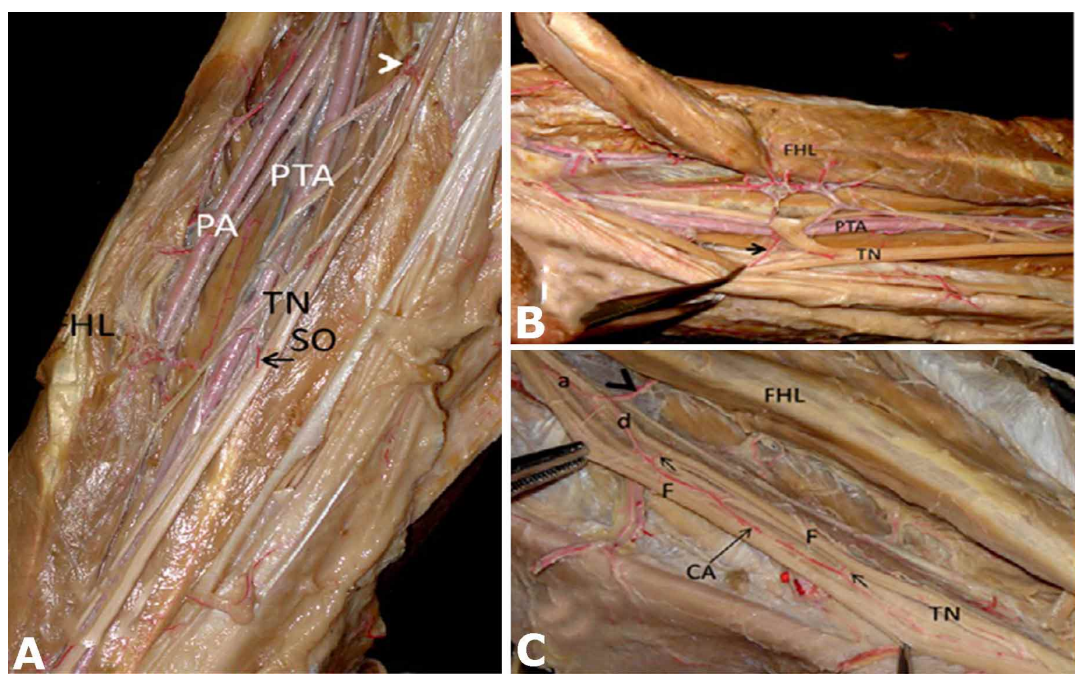

Fig. 4. Arterial Pedicle and Fibular Artery B. is a magnified portion of $\mathrm{A}$. They show arterial pedicle (arrow) from the fibular artery (FA) that gives ascending (a) and descending (b) branches in a mesentery-like structure (me) in the outer sheath of the tibial nerve (TN). These branches form a central artery (CA) inside the nerve and another feeding pedicle (arrow head) from the fibular artery that joins the central longitudinal artery (CA). FHL, flexor hallucis longus, v1 \& v2 are vena comitantes

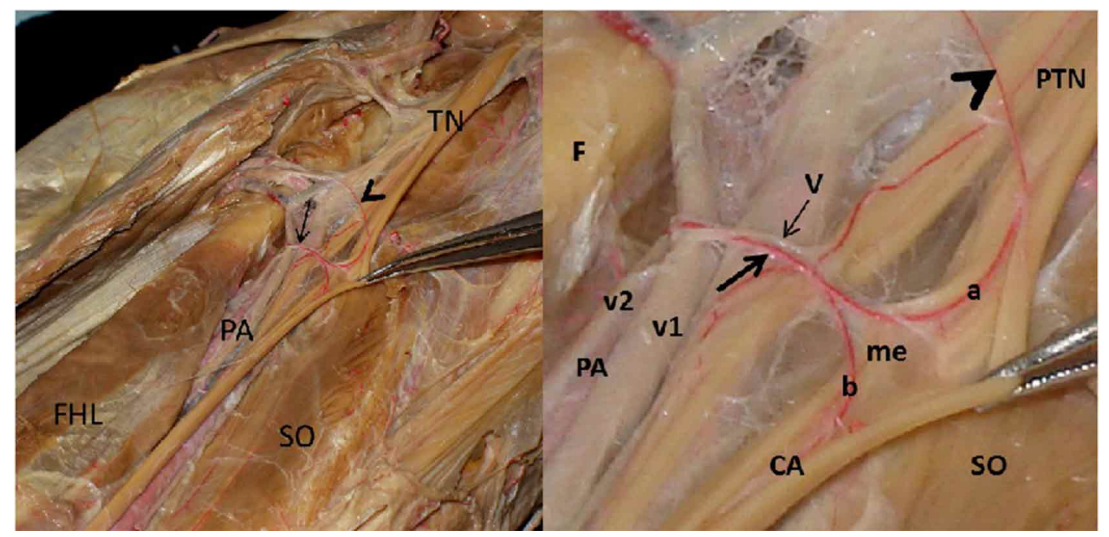

Fig. 5. Arterial Pedicles of Posterior Tibial Artery A. shows arterial pedicles (arrows \& arrow heads) of posterior tibial artery (PTA); $\mathrm{HL}$; flexor halluces longus, SO; flexor digitorum longus. B. has shown arterial pedicle (arrow head)from the fibular artery and the posterior tibial artery (PTN) (short arrow). The tibial nerve is bisected by the tributaries of the vena comitantes (long arrow) accompanying the posterior tibial artery (PTA), FHL; flexor hallucis longus muscle. $\mathrm{C}$ shows ascending (a) and descending (d) branches in the outer sheath of the tibial nerve (TN) to form a central longitudinal tortuous artery (CA) that gave branches (arrows) to the nerve fascicles $(\mathrm{F})$.

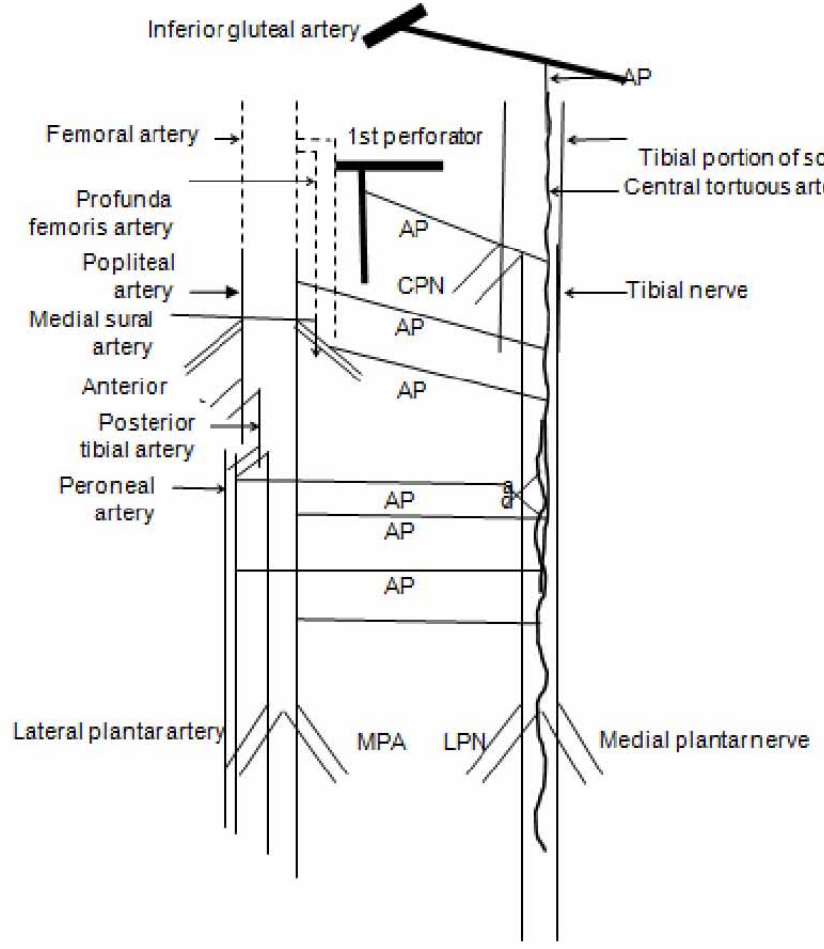

Fig. 6. Diagrammatic illustration of the arterial supply of the tibial portion of the sciatic nerve and the tibial nerve; AP; arterial pedicle, CFN; common fibular nerve, LPN; lateral plantar nerve, MPA; medial plantar artery, $\mathrm{a}$ and $\mathrm{b}$ are ascending and descending branches. 


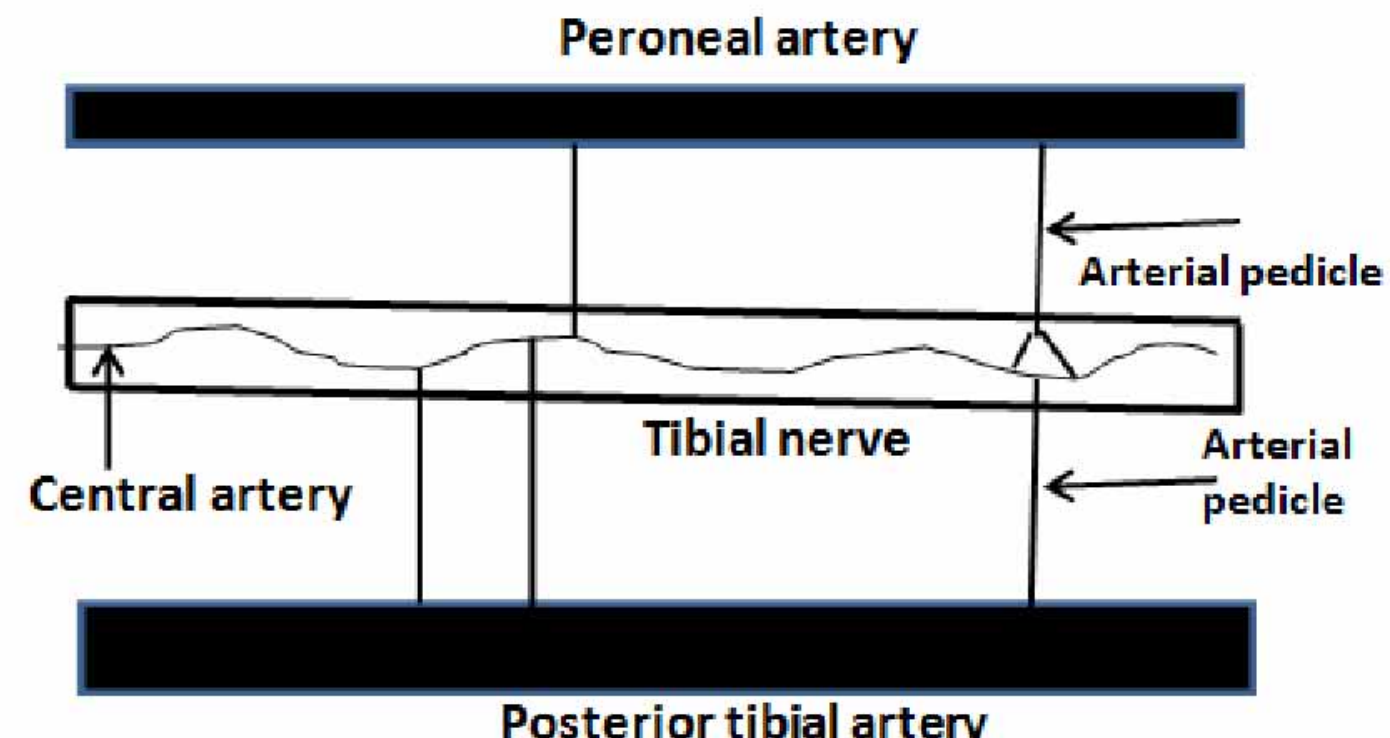

Fig. 7. The central artery of the tibial nerve is shared by the feeding pedicles.

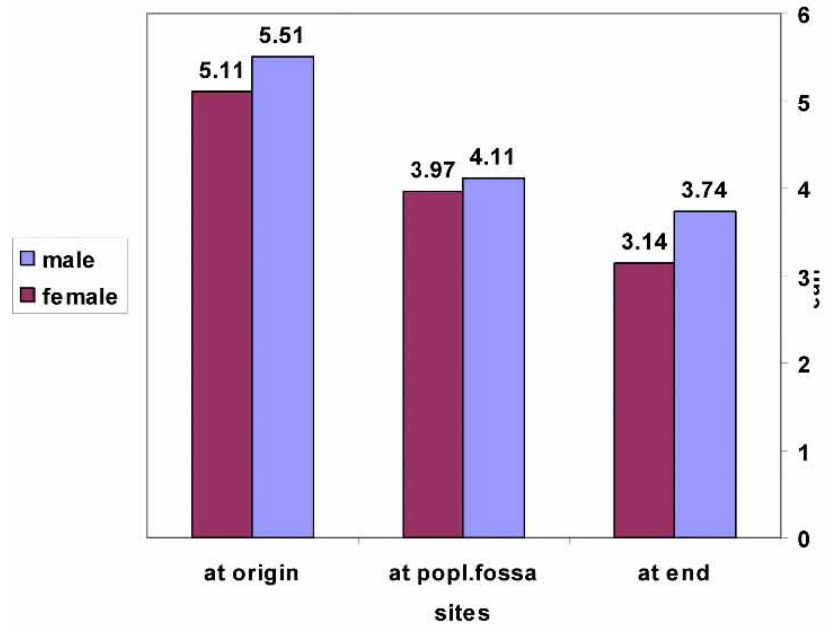

Fig. 8. It shows the differences of the diameter of the tibial nerve (in $\mathrm{mm}$ ) in male and female at different sites.

\section{DISCUSSION}

Posterior tibial nerve has various clinical applications. Its stimulation is effective in the treatment of non-neurogenic overactive bladder among children and women (Kummer et al., 1994). Similarly, it is also useful and safer option in a management of neurogenic lower urinary tract dysfunction (Preyer et al., 2015). It is also recommended in the treatment of refractory cases of urinary dysfunction in children (Schneider et al., 2015), in urinary fecal incontinence (Patidar et al.), and in the treatment of chronic anal fissures (Lecompte et al., 2015). The procedure proved to have fewer side effects; commonly pain at the site of stimulation. Therefore it is superior to other treatment modalities (Flores; Rangel et al., 2011; Burton et al., 2012; Martín et al., 2012).

Percutaneous tibial nerve stimulation was reported in the treatment of fecal incontinence (Manríquez et al., 2016), for the treatment of refractory spastic foot and its consequences (Ducic \& Felder, 2012), and for suppression of irritation induced bladder over activity (Fouad, 2011; Tai et al., 2011). Tibial nerve block was reported as a safe and effective method for controlling pain after outpatient surgery of hallux valgus (Burton et al.). The precise location of the surface anatomy of the nerve in the popliteal fossa is of extreme important in certain selective tibial nerve block, which is used for postoperative analgesia after total knee arthroplasty in combination with the femoral nerve block. Tibial nerve decompression by the release of known anatomical compression points, the soleus arch, and the tarsal tunnel, can be accomplished safely and effectively via minimized skin incisions (Martín et al.).

The blood supply of the posterior tibial nerve is crucial in recovery following its decompression and for perfect stimulation. Moreover, vascularized nerve grafts were found to result in rapid and sound nerve repair; in this respect, the length, diameter and blood supply is 
extremely important. The current study showed that the total length of the tibial nerve was at a mean of $65.26 \pm 14.42$ $\mathrm{cm}$ in males and $64.79 \pm 67.61 \mathrm{~cm}$ in females without significant difference in both sexes. Also, its diameter at beginning, at the popliteal fossa, and at its end showed no significant differences in males and females. However, in both sexes, the diameter of the nerve progressively decreased as the nerve passes distally. It was at a mean of $5.51 \pm 1.55 \mathrm{~mm}$ at its origin and at a mean of $3.74 \pm 0.81$ $\mathrm{mm}$ at its end. The nerve received different arterial pedicles from the popliteal artery in the popliteal fossa, and from the fibular and posterior tibial arteries at the back of the leg. These arterial pedicles shared in a continuous central tortuous artery inside the nerve among its fascicles. Such an arrangement could be useful to maintain the arterial supply to the tibial nerve in different movements and positions. It also explains its adaptation to stretch at different movements of the ankle or even compression (Apaydin et al.). Moreover, it is helpful to get vascularized tibial nerve grafts depending on one large arterial pedicle when needed.

The fibular artery or the posterior tibial artery (mean diameter was $3.38 \pm 0.1 \mathrm{~mm}$ and $4.24 \pm 0.2 \mathrm{~mm}$ respectively) could be elevated with a segment of the nerve, and can be transferred to distant areas as a free vascularized nerve graft. The presence of the central artery was helpful to maintain the blood supply of the free segment of nerve. Moreover, vascularized peroneus brevis or longus muscle graft with the removal of the fibular artery has not affected the vascularity of the tibial nerve. Since feeding vessels from the posterior tibial artery maintain the central artery within the tibial nerve, and maintain its blood supply. Occlusion of one of these pedicles during walking, running or sitting could not severely affect the vascularity of the nerve. The large diameter and reasonable length on the back of the leg together with rich arterial supply and with presence of a large feeding artery can be a reason for successful free vascularized tibial nerve grafts. A number of the arterial pedicles were found during the current study to be more increased at the back of the leg distal to the popliteal fossa, which originated from the fibular and posterior tibial arteries. Elevation of a vascularized segment of the tibial nerve in the leg, distal to the popliteal fossa, would not seriously affect the movements of the leg. The extensor and fibular (lateral) compartments of the leg are intact together with gracilis, popliteus, and soleus muscles. Movements of the ankle joint might not be seriously deteriorated (Ahmad et al., 2012). Tibial neurotomy has also been advised as a treatment of lower limb spasticity (Buffenoir et al., 2004).

There is an origination from different anastomoses and sources, which are mutually held in connective tissue sheaths in regards of nerves and arteries, as well as within nerves fascicles and between the nerve fibers. There is a level of overlapping among vascular territories that allows preservation of blood and collateral circulation supply in situations, where one or more regional vasa nervorum is interrupted. The pattern of vascularization is present in the major trunk of the tibial and sciatic nerves. Two to six arteries are needed to form the extraneural arterial chain of the sciatic nerve, which pass to it from neighboring arteries, perforating, popliteal artery, inferior gluteal, and medial circumflex femoral at the certain level (Ugrenovic et al., 2013).

Constant compression and stretching are exposed by the nerve of the limbs, especially the lower limb during routine activities. Nerve pulses are commonly conducted by the nerve fiber. Besides special connective tissue sheaths, which protects them from compression and stretching, the arterial arrangements of peripheral nerves might be planned to make sure the preservation of blood supply. The tibial nerve has an adequate length and diameter with a good blood supply. Consequently, it could be used as allogenic vascularized nerve graft after limb salvage with the presence of specialized nerve banks in the future. It will be probably more useful to repair sizable nerves.

ELBARRANY, W. G. \& ALTAF, F. M. El nervio tibial y su vasculatura: Una evaluación anatómica. Int. J. Morphol., 35(3):812819, 2017.

RESUMEN: El estudio ha contribuido a evaluar anatómicamente el nervio tibial y su vasculatura. Se han utilizado diez cadáveres preservados ( 5 hombres, 5 mujeres) para este estudio. Cada cadáver fue inyectado con látex rojo y a través de incisiones el nervio tibial fue expuesto al nivel de la bifurcación del nervio ciático. El nervio tibial en el $85 \%$ de los cadáveres se localizó entre los tercios medio e inferior en el ángulo superior de la fosa poplítea; mientras que en el $15 \%$ de los cadáveres estaba presente debajo del músculo piriforme en la región glútea. La longitud total media del nervio tibial fue de $65,26 \pm 14,42 \mathrm{~cm}$ en hombres y $64,79 \pm 67,61 \mathrm{~cm}$ en mujeres, sin diferencias significativas. Su diámetro total se situó en una media de 5,51 $\pm 1,55 \mathrm{~mm}$, con una media de 4,11 $\pm 0,88 \mathrm{~mm}$ en la fosa poplítea y una media de $3,24 \pm$ $0,81 \mathrm{~mm}$ en su terminación profunda al retináculo flexor en cadáveres masculinos. En mujeres; Las medias fueron 5,11 $\pm 0,21 \mathrm{~mm}$, $3,97 \pm 1,78 \mathrm{~mm}$ y $3,14 \pm 0,03 \mathrm{~mm}$, respectivamente, sin diferencia significativas. Se concluyó que el nervio tibial tiene suficiente y buen suministro de sangre. Además, se puede utilizar como injerto de nervio vascularizado alogénico para reparar nervios importantes después de la recuperación de miembros.

PALABRAS CLAVE: Tibia; Arteria peroneal; Arteria tibial posterior; Injertos de nervios vascularizados. 


\section{REFERENCES}

Ahmad, M.; Tsang, K.; Mackenney, P. J. \& Adedapo, A. O. Tarsal tunnel syndrome: A literature review. Foot Ankle Surg., 18(3):149-52, 2012.

Apaydin, N.; Loukas, M.; Kendir, S.; Tubbs, R. S.; Jordan, R.; Tekdemir, I. \& Elhan, A. The precise localization of distal motor branches of the tibial nerve in the deep posterior compartment of the leg. Surg. Radiol. Anat., 30(4):291-5, 2008.

Boudaoud, N.; Binet, A.; Line, A.; Chaouadi, D.; Jolly, C.; Fiquet, C. F.; Ripert, T. \& Merol, M. L. Management of refractory overactive bladder in children by transcutaneous posterior tibial nerve stimulation: A controlled study. J. Pediatr. Urol., 11(3):138.e1-10, 2015.

Bradley, J. L.; King, R. H.; Muddle, J. R. \& Thomas, P. K. The extracellular matrix of peripheral nerve in diabetic polyneuropathy. Acta Neuropathol., 99(5):539-46, 2000.

Buffenoir, K.; Roujeau, T.; Lapierre, F.; Menei, P.; Menegalli-Boggelli, D.; Mertens, P. \& Decq, P. Spastic equinus foot: multicenter study of the long-term results of tibial neurotomy. Neurosurgery, 55(5):1130-7, 2004.

Burton, C.; Sajja, A. \& Latthe, P. M. Effectiveness of percutaneous posterior tibial nerve stimulation for overactive bladder: a systematic review and meta-analysis. Neurourol. Urodyn., 31(8):1206-16, 2012.

Ducic, I. \& Felder, J. M. 3rd. Tibial nerve decompression: reliable exposure using shorter incisions. Microsurgery, 32(7):533-8, 2012.

Flores, L. P. Proximal motor branches from the tibial nerve as direct donors to restore function of the deep fibular nerve for treatment of high sciatic nerve injuries: a cadaveric feasibility study. Neurosurgery, 65(6 Suppl.):218-24, 2009.

Fouad, W. Selective neurotomy of the tibial nerve for treatment of spastic foot. Alex. J. Med., 47(4):325-31, 2011.

Kogawa, S.; Yasuda, H.; Terada, M.; Maeda, K. \& Kikkawa, R. Apoptosis and impaired axonal regeneration of sensory neurons after nerve crush in diabetic rats. Neuroreport, 11(4):663-7, 2000.

Kummer, W.; Seifert, E. \& Schadel, A. Innervation of epi- and endoneurial compartments of rat facial, vagus and sciatic nerves as studied by doublelabeling immunofluorescence. Acta Anat. (Basel.), 149(4):264-71, 1994.

Lecompte, J. F.; Hery, G.; Guys, J. M. \& Louis-Borrione, C. Evaluation of transcutaneous electrical posterior tibial nerve stimulation for the treatment of fecal and urinary leaks in children: preliminary results. $J$. Pediatr. Surg., 50(4):630-3, 2015.

Manríquez, V.; Guzmán, R.; Naser, M.; Aguilera, A.; Narvaez, S.; Castro, A.; Swift, S. \& Digesu, G. A. Transcutaneous posterior tibial nerve stimulation versus extended release oxybutynin in overactive bladder patients. A prospective randomized trial. Eur. J. Obstet. Gynecol. Reprod. Biol., 196:6-10, 2016.

Martín, M. A.; Ollé, G.; Pellejero, J. A.; Torruella, R.; Yuste, M. \& Pou, N. Comparison of the post-surgical analgesic effectiveness of tibial (at internal malleolus level) and common peroneal nerve block with infiltration of the surgical wound in Outpatient Surgery of the hallux valgus. Rev. Esp. Anestesiol. Reanim., 59(4):197-203, 2012.

Ndiaye, A.; Dia, A.; Konate, I.; Diop, M. \& Sow, M. L. Topographic anatomy of the tibial nerve in the medial malleolus: application to the effect of nerve block anesthesia. Morphologie, 87(277):25-7, 2003.

Patidar, N.; Mittal, V.; Kumar, M.; Sureka, S. K.; Arora, S. \& Ansari, M. S. Transcutaneous posterior tibial nerve stimulation in pediatric overactive bladder: A preliminary report. J. Pediatr. Urol., 11(6):351-e1-6, 2015.

Preyer, O.; Umek, W.; Laml, T.; Bjelic-Radisic, V.; Gabriel, B.; Mittlboeck, M. \& Hanzal, E. Percutaneous tibial nerve stimulation versus tolterodine for overactive bladder in women: a randomised controlled trial. Eur. J. Obstet. Gynecol. Reprod. Biol., 191:51-6, 2015.

Rangel, V. de O.; Carvalho, R. de A.; Mandim, B. L.; Alves, R. R.; Ruzi, R. A. \& da Fonseca, N. M. Tibial and common fibular nerve block in the popliteal fossa with single puncture using percutaneous nerve stimulator: anatomical considerations and ultrasound description. Rev. Bras. Anestesiol., 61(5):533-43, 2011.

Schneider, M. P.; Gross, T.; Bachmann, L. M.; Blok, B. F.; Castro-Diaz,
D.; Del Popolo, G.; Groen, J.; Hamid, R.; Karsenty, G.; Pannek, J.; Hoen, L. \& Kessler, T. M. Tibial nerve stimulation for treating neurogenic lower urinary tract dysfunction: A systematic review. Eur. Urol., 68(5):859-67, 2015.

Schupeck, M.; Ward, K. K.; Schmelzer, J. D. \& Low, P. A. Comparison of nerve regeneration in vascularized and conventional grafts: nerve electrophysiology, norepinephrine, prostacyclin, malondialdehyde, and the blood-nerve barrier. Brain Res., 493(2):225-30, 1989.

Shacklock, M. Clinical Neurodynamics: A New System of Musculoskeletal Treatment. Edingburgh, Elsevier, 2005.

Standring, S. Gray's Anatomy. The Anatomical Basis of Clinical Practice. $39^{\text {th }}$ ed. Edinburgh, Elsevier Churchill Livingstone, 2005. pp.1489-505.

Tai, C.; Chen, M.; Shen, B.; Wang, J.; Roppolo, J. R. \& de Groat, W. C. Irritation induced bladder overactivity is suppressed by tibial nerve stimulation in cats. J. Urol., 186(1):326-30, 2011.

Ugrenovic, S. Z.; Jovanovic, I. D.; Kovacevic, P.; Petrovic, S. \& Simic, T. Similarities and dissimilarities of the blood supplies of the human sciatic, tibial, and common peroneal nerves. Clin. Anat., 26(7):875-82, 2013.

Yasuda, H. \& Dyck, P. J. Abnormalities of endoneurial microvessels and sural nerve pathology in diabetic neuropathy. Neurology, 37(1):20-8, 1987.

\section{Corresponding author: \\ Wagih G. Elbarrany \\ Anatomy Department \\ Faculty of Medicine \\ Umm Al-Qura University \\ Makkah \\ SAUDI ARABIA}

E-mail: elbarrany@yahoo.com

Received:11-12-2016

Accepted:13-03-2017 